\title{
The State of Postsecondary Education for Persons with Intellectual Disabilities: What Are the Perceptions of Key Stakeholders?
}

\author{
Colleen Thoma ${ }^{1}$, Kira Austin ${ }^{1}$, Edwin Achola ${ }^{1}$, Cecilia Batalo ${ }^{1}$, Dawn Carlson ${ }^{2}$, \\ Kim Boyd $^{3}$, Leslie Bozeman ${ }^{1}$, Diane Wolfe ${ }^{4}$ \\ ${ }^{1}$ School of Education, Virginia Commonwealth University, Richmond, USA \\ ${ }^{2}$ National Institute on Disability and Rehabilitation Research, US Department of Education, \\ Washington DC, USA \\ ${ }^{3}$ Department of Special Education, Chesterfield County Public Schools, Midlothian, USA \\ ${ }^{4}$ Department of Special Education, Fluvanna County Public Schools, Palymyra, USA \\ Email: cathoma@vcu.edu
}

Received August 24 ${ }^{\text {th }}$ 2012; revised September 22 ${ }^{\text {nd }}, 2012$; accepted October 10 ${ }^{\text {th }}, 2012$

\begin{abstract}
Evidence indicates that post-high school outcomes for students with disabilities look different from the post-high school outcomes of a traditional high school graduate and vastly different from a student without disabilities who has the opportunity to go to college. In fact, these statistics are widely used to advocate for increased efforts to providing access to higher education opportunities for students with and without disabilities. Beyond descriptive literature, little information is available on the current state of knowledge in the field of post secondary education for students with ID. This qualitative investigation examined transcripts generated from presentations by a variety of experts in the field of PSE-providing an overview of knowledge on PSE for students with ID. Among other important findings, this study indicates that there is limited clarity on the outcomes of participating in PSE, economics of higher education and foundation of evidence on providing PSE for students with intellectual disabilities. The implications of these findings for future research, policy and practice are also presented.
\end{abstract}

Keywords: Postsecondary Education; Intellectual Disabilities; Qualitative Study

\section{Introduction}

The need for postsecondary education has increased greatly in the past decade. Educators are just now beginning to understand exactly how important it is for all students with and without disabilities. In 2009, President Barak Obama spoke powerful words in his State of the Union address in regards to America's changing educational system:

In a global economy where the most valuable skill you can sell is your knowledge, a good education is no longer just a pathway to opportunity; it is a prerequisite. Right now, three-quarters of the fastest growing occupations require more than a high school diploma. And yet, just over half of our citizens have that level of education. We have one of the highest high school dropout rates of any industrialized nation, and half of the students who begin college never finish.... But it is the responsibility of every citizen to participate in it [educational system]. So tonight I ask every American to commit to at least 1 year or more of higher education or career training. This can be community college or a 4-year school, vocational training or an apprenticeship. But whatever the training may be, every American will need to get more than a high school diploma. (Obama, 2009: para. 61).

There are several economic, work-related, and social benefits associated with postsecondary education. One such benefit in- cludes increased earnings over a lifetime. The Institute for Higher Education Policy reported those with a bachelor's degree would earn about $75 \%$ more over a lifetime as compared to those with a high school degree (Baum \& Payea, 2004). Higher levels of education also correspond with lower levels of unemployment (Baum \& Ma, 2007). Other associated benefits include improved health, increased lifespan, and higher reported happiness (McMahon, 2009).

These improved employment outcomes as a result of participation in higher education have received a great deal of attention from the field of special education in recent years. This is due, in part, from the consistently poor post-school outcomes for students with disabilities, and in particular, outcomes related to employment. The Bureau of Labor Statistics (2010) reported that only $22 \%$ of all adults with disabilities participated in the labor force as compared to $70 \%$ of those without disabilities. Individuals with disabilities are more likely to have less job experience and earn lower incomes than persons without disabilities (National Longitudinal Transition Study-2, 2003). Evidence indicates that post-high school outcomes for students with disabilities look different from the post-high school outcomes of a traditional high school graduate and vastly different from a student without disabilities who has the opportunity to go to college. In fact, these statistics are widely used to advocate for increased efforts to provide access to higher education opportunities for students with and without disabilities (Stodden, 2005).

In 2008 the Higher Education Act (PL 89-329) was reauthorized as the Higher Education Opportunity Act of 2008 (PL 
110-315) (HEOA), and for the first time the law specifically gave students with intellectual disabilities (ID) the opportunity to attend institutions of higher learning. Opportunities included attending postsecondary education through dual enrollment at both the high school and institution of higher education, auditing a course, or enrollment in specialized postsecondary education (PSE) programs. While there have been a number of PSE programs for students with disabilities, and particularly for students with intellectual and developmental disabilities, that preceded this change in the Higher Education Act, the inclusion of support for these programs facilitated the integration of students with ID into the PSE community. It raised awareness that students with ID could attend college, regardless of the form or severity of their ID, and helped universities overcome some of the barriers to participation in PSE programs through three key provisions. The first such provision waives the high school diploma or certificate of completion requirement for enrollment in PSE. Prior to this provision, students with ID who did not earn a high school diploma were generally not found to be eligible to enroll in a PSE program. In addition, the HEOA provided a mechanism for assuring that students attending specialized PSE programs for students with ID could apply for financial assistance to help cover some of the tuition and fees.

The HEOA also subsidized efforts to implement additional programs as well as conduct research on their effectiveness through the establishment of a number of model demonstration centers and one coordinating center. These efforts were initiated for the purpose of exploring best practices for admitting, teaching, retaining, integrating, and preparing students with ID for work and career. The Office for Postsecondary Education (OPE) funded 27 centers with the aim of creating or expanding "programs that focus on academics and instruction, social activities, employment experiences through work-based learning and internships, and independent living. Grantees will provide individualized supports for students and opportunities to be involved in college experiences with their peers without disabilities (U.S. Department of Education, 2010).”

The National Institute on Disability and Rehabilitation Research (NIDRR) also funded a center on postsecondary education for students with ID. The center's research activities included a survey of existing PSE programs for students with ID, and analyses of secondary data sets such as the National Longitudinal Transition Study-2 (NLTS-2) and the Rehabilitation Services Administration Case Service Report (RSA-911) vocational rehabilitation outcomes database in order to obtain a better understanding of the characteristics of students with ID who most likely attended, or wished to attend, these existing postsecondary education programs.

In 2007, NIDRR called for proposals to conduct research on PSE for students with ID. It became apparent that there was, and continues to be, a very limited understanding of exactly what happens to students with ID who wish to pursue PSE. A small number of researchers and advocates have suggested that young persons with ID who had some form of PSE demonstrated improved social skills, better independent living skills, and better employment outcomes when compared to students with ID who did not receive PSE (Casale-Giannola, \& Kamens, 2006; Dolyniuk et al., 2002; Hamill, 2003; Zafft, Hart, \& Zimbrich, 2004).

In 2011, Thoma et al., (2011) completed a review of the literature from the past ten years to identify current research of postsecondary programs for students with ID to determine if the evidence validates the assumptions of the field that PSE results in improved outcomes for students with ID. The review illuminated that PSE for students with ID is still very rare, and the majority of research studies are descriptive in nature. Most research in this area describes specific programs at institutions of higher education or an individual student's experience. Overall, studies reported positive experiences for individual students with ID who participated in PSE; however there is little empirical evidence to support claims that the same kind of improved outcomes exist for other groups of students who go on for PSE. Zafft et al. (2004) demonstrated that students with ID who participated in PSE had improved employment outcomes as compared to their peers who remained in a high school setting, but this was the only study that attempted to examine outcomes from programs in a systematic way.

The phenomenon of students with ID participating in postsecondary education is still in a developmental stage. Very little is known about how those involved understand and participate in this experience. In addition, Thoma et al. (2011) also found that PSE programs for students with ID can be very different in the types of services they provide, the anticipated outcomes expected, and the degree to which students are included in the life of the university/college. In order to better understand this phenomenon, the researchers sought to gather information from those who are experts in the area of postsecondary education, to determine what is currently known about the field beyond what has been published in the literature.

\section{Methods}

\section{Setting}

Growing interest in understanding the phenomenon of including students with ID in PSE caused NIDRR, in conjunction with OPE, to issue invitations to over 65 persons representing a wide variety of stakeholders to attend a one day State of the Science Conference on PSE for students with ID (2009). The conference was held on the campus of George Mason University on November 6, 2009.

The morning of the conference was reserved for 16 presentations providing an overview of what knowledge of PSE for students with ID was available at the time. A comprehensive literature review was prepared by NIDRR staff and distributed to conference participants prior to the meeting. The afternoon sessions were structured to allow for the intense exploration and discussion of research, policy and practice related to specific topics for an agenda of activities that would help the field of PSE for students with ID establish itself and grow. One or more well-known stakeholders in the field typically mediated sessions allowing participants both to comment and ask questions of others in the session.

\section{Participants}

Forty-three experts participated in the working group sessions at the State of the Science Conference. This number of participants allowed the researchers to find rich descriptions from the transcripts necessary to draw meaningful themes from the qualitative data (Geertz, 1973). Participants in these sessions included leading researchers, practitioners, advocates, and policy advisors concerned with the current state of knowledge in the field of PSE for students with ID. The breakout sessions were structured in two waves. During the first wave participants 
were assigned to either Group 1 or Group 2. The second wave consisted of three different groups: Group 4, Group 5, and Group 6. In the breakout sessions, participants were assigned to different discussion groups, depending on their area of expertise/focus. Table 1 provides an overview of the sessions and the number of participants assigned to each.

\section{Data Collection}

During each breakout session, participants were asked to reflect on current practices related to the topic, the challenges they faced in addressing the topic or meeting the needs of students with ID related to the topic, as well as what they perceived to be their need for research to guide the further improvement of practices related to the topic (Wenger, 1998). The facilitator's role was to guide the discussion to assure that all participants had an opportunity to contribute and to summarize the key points from the discussion when the larger group came back together to share their results. In addition, the participants were asked to discuss how their practices were related to the research literature review shared with them prior to their attendance at the conference. In all, five broad areas ranging from student specific interests and needs to macro-structural trends in PSE practice and regulation underwent intense review and scrutiny.

The transcripts for each breakout session were used as the data analyzed for this study. Extensive notes were taken, and all conversations were transcribed verbatim by a court reporter. A total of more than 500 pages of transcripts were obtained. This rich source of information about PSE practices, challenges, and directions for the future provided an opportunity for the field to learn from the experiences of university program faculty, parents, advocates, and national policy advocates, which is particularly critical given the very limited research in this area. It also provided an opportunity to learn what those experts believe to be the critical issues to address as they met to discuss them. Perakyla (2005) points out that although most qualitative studies rely on interviews as a way of collecting data, there are benefits in analyzing data collected from more "natural" interactions. These transcripts provided insight not only on the perceptions of the various stakeholders, but also the ways in which these different individuals come together to address the challenges in the field.

\section{Data Analysis}

The analysis of the transcripts was conducted in multiple stages using a constant comparative method (Corbin \& Strauss,
2008). To increase the credibility of the findings, investigator triangulation was used throughout the data analysis. The tran scripts were reviewed by a total of six researchers serving a variety of research perspectives. It is this triangulation of perspectives that provides a less biased review of the transcripts and increases the credibility of the findings. These reviewers brought immense levels of varying experiences and expertise with regards to transition for individuals with ID and qualitative research methodology. The primary author, an experienced qualitative researcher in the field of transition for individuals with ID, facilitated the qualitative review of data. The facilitator aided in the development of research teams, facilitated team meetings, and provided guidance regarding the overall data analysis process.

Prior to research teams being established, all six reviewers watched video clips of the morning presentations that were part of the 2009 conference, recorded memos of their biases, and then shared these biases with the larger team. These perspectives helped to form smaller working groups by which the transcripts were analyzed. Such biases ranged from ardent support for post secondary education for learners with ID to skepticism about the same. All smaller workgroups had a member from each side of the spectrum as a way of bringing multiple perspectives to the review and analysis of the data. In addition, one person experienced in qualitative research methodology but with little knowledge of PSE programs for students with ID, reviewed all transcripts separately as a last step in the data analysis process to further enhance the credibility of the findings.

Saldana (2009) recommended two rounds or steps to the qualitative data coding process. In each stage, researchers choose both the method and analytical approach based on the type of data to be coded, the strengths or experience of the coders, and the purpose of the study. In the first cycle of this study, the researchers used descriptive coding (Saldana, 2009) which provided an opportunity to summarize the topics addressed by the discussion groups. Initially two working groups of two were developed with each analyzing half of the transcripts. Two additional researchers were brought in to examine all of the transcripts independently. Their unique perspectives included experience with students with ID, but not in the area of transition, and experience with postsecondary education, but not with students with ID. All six reviewers read through their sections of the transcripts individually, isolating emerging themes and corresponding quotes, before sharing their findings with their research partner and later with the larger team during the second cycle of the data analysis process.

The first round of open coding yielded an assortment of themes, which were then shared across the two work groups.

Table 1.

State of the science conference working group descriptions.

\begin{tabular}{ccc}
\hline Group & Discussion Focus Area & \# of Participants \\
\hline 1 & Research needs regarding students with ID in PSE programs in relatively broad terms. & 22 \\
2 & Research needs concerning PSE program characteristics and the broader context in which these programs exist and operate. & 21 \\
3 & Detailed exploration of ways in which students with ID can be studied. & 14 \\
4 & Deepened discussion of research needs and practices in the area of PSE programs and their characteristics. & 15 \\
5 & Focus on how the broader, social, political, and administrative environments affect the development and growth of PSE & programs for students with ID. \\
\hline
\end{tabular}


This ensured that these early ideas were based on the data at hand. The second round of data analysis focused on reorganizing and re-conceptualizing the codes and themes identified from the first round of coding. This study used a form of "focused coding" (Saldana, 2009: p. 151) to reorganize the data into the overarching themes. The three teams worked together to conduct the final selective coding and categorization of data into broad conceptual frameworks. A theme such as outcomes was inferred from social engagement, independence, and employment, which had been coded as separate themes in the initial coding. Group consensus was used to finalize the themes that emerged from this data.

This rigorous analysis of transcripts yielded five themes: outcomes, self-determination, funding, program design, and research. These themes are described in detail below, in order of the number of comments or recommendations that fit within that theme. This order does not necessarily reflect the importance of one theme over the other themes, either by the authors or by the participants of the conference.

\section{Themes}

\section{Outcomes}

The value of understanding the outcomes of PSE was accentuated by a sizable portion of participants who felt that the there were a number of important outcomes for students with ID that supported their entering post secondary institutions, including better access to competitive employment, improved academic performance, social engagement and independent living. A contributor thus indicated,

"I'd like to say that employment is perhaps the most important outcome, but it's not enough. We also need to be looking at least academics: and you know, socialization, I think is the term that is often used. I really mean social engagement, and independent living. So there are four: academics, employment, independent living and social engagement."

The determination of important outcomes appeared to revolve around the need to invite the opinions of the learners going through these programs. Some participants felt that rather than stating what stakeholders hope these programs will engender, it would be prudent to inculcate students' expectations. A contributor thus said, "and I think what may be an area of qualitative research is to ask the students, what do you think about what the outcome should be-when they start the program?"

With these outcomes discussed, the question of how they are to be measured also arose, considering that there are multiple ways in which these outcomes can be assessed. While it is relatively easy to measure employment outcomes through determining the number of program participants who have a job upon exiting the program, and/or comparing wages of those who participate compared to those who do not, the participants acknowledged that it was much more difficult to measure the other important outcomes for students with ID. They discussed the components of social engagement and independence that would be outcomes of participation in PSE programs and therefore should be measured. Participants identified the need to determine whether or not an individual is experiencing the following: greater independence, better language skills, better reasoning, and greater self-determination, has received certification in a specific work or living skill, and displays better social skills or is participating in more meaningful relationships. These thoughts were embodied in quotes such as, "Is the outcome independent living, greater independence, greater self directedness, employment? Is there some kind of certification that anybody is finding for their students? Do they really have more significant relationships, rather than... like just a relationship where people are befriending them? Are they really calling them on Saturday nights to go do things? ... do you want to go to a frat party?"

The subject of outcome measurement was also examined from the prism of the achievement of these learners compared to the strides they made based on high school education. Some contributors felt PSE should produce outcomes dissimilar from those yielded by high school curriculum. A participant thus indicates, "Some of them graduate and they are back to where they were." In light of the above expectations, participants also explored the subject of how postsecondary programs can be set up to specifically address these outcomes. Threads of discussion that buttressed this subject included ones such as "How is the curriculum developed towards a particular pointed outcome?" and "We need to look at how effective the programs are at creating those outcomes for the individuals in them."

\section{Self-Determination}

Self-determination as a critical outcome got notable examination by a host of contributors in the conference. This discourse spun around concepts such as how postsecondary programs can enable learners with ID to become their own best natural supports, the scope of self-determination in view of functional deficits, and the measurement of self-determination. Participants talked about the need to distinguish ways in which the programs facilitate the development of self-determination competencies through approaches such as counseling; whether PSE actually inculcates self-determination, and the contribution of self-determination in the realization of other outcomes (not sure this sentence is clear to the reader). This conversation is encapsulated in questions and statements such as these: "Are they being counseled and what are they doing with that information to be self-determined." "Do the post secondary experiences increase self-determination and then does that further enhance those outcomes?" and "Is a student able to have characteristics of self-determination-self awareness?"

Some participants also brought up the subject of scope of self-determination in terms of what the learners will actually be permitted to determine, and affording opportunities to exercise self-determination within the postsecondary setting. One asked, "What do we let them determine?" Similarly, another stated, “... a world where students are actually enabled to choose something other than whatever program [for individuals with disabilities] they know about.” The better part of the discussion on self-determination focused on its assessment, both in terms of a baseline measure as well as a way to track what was believed to be improvement over time. This involved questions on how to determine progress in advancement of self-determination and the availability of opportunities to develop the competency. Some participants thus recommended that a common measure be used not only in a specific program, but for all individuals with ID in PSE programs. One participant articulated 
"... that everyone who had incoming freshmen take the self-determination scale; and see if we can correlate that at the end when they graduate, ... as some kind of unit measurement...?” Another participant recommended that programs identify "...proactive ways of measuring a young person with a disability's opportunity and, ability to promote their self-determination and self-advocacy skills.”

\section{Funding}

Funding was also identified as critically important to the existence and success of programs. It was clear that experts identified a number of different funding sources, but they struggled to access them equally and/or find organized ways to advocate for the additional funding they needed to provide an adequate level of supports and services for students with ID. One participant at the conference on PSE for young adults with ID characterized the concerns regarding funding:

"The third major category is, what are the economics? I talked about that a little bit above, the funding. But how much does it cost? Who is paying? What are the ways that colleges and universities are providing in kind or other support? And [how do we determine] the return on investment."

Through qualitative analysis of the transcripts, it became apparent that young adults with ID are often told they are not able to participate in postsecondary educational opportunities due to limited resources. These stakeholders believed that extensive levels of support, which expand the financial burden for these young adults, are needed in order for them to participate in PSE. There is a significant differential with regard to the cost for young adults with disabilities to have these same postsecondary educational opportunities as those without disabilities. This was acknowledged in every group focus meeting when funding was discussed.

Funding awareness is a necessary critical component in order to be able to make informed decisions regarding PSE program design, growth, and sustainability. This is reflected as one participant questioned, "What are the different funding streams? What are the different ways we maybe could reconceptualize the funding?" Through identification of the funding streams and determination of how funds are being used, comparisons to programs for young adults without disabilities can be made. Through this avenue, the possibility of gaining new resources and/or redirecting existing resources was discussed. Some of the agencies identified by the focus group that may provide funding are vocational rehabilitation, independent living centers, developmental disability (DD) agencies, and school districts.

Once funding sources are identified, the focus group participants acknowledged that access to the funds would be a challenge for these young adults with ID. These individuals were identified as being at the bottom of the disabilities pyramid with limited ability to gain access to funding. The main point that surfaced in regard to this issue was the return on investment; that is, what are we getting for this allocation of funds, bringing the discussion of funding back to outcomes and their measurement. But this discussion added a distinction to the need to identify the outcomes of PSE programs and to measure them: the purpose of this activity was to inform the various funding agencies that this was a worthwhile investment for the future, not just an expendable "feel-good" program. The participants were unified in their belief that these programs provided a positive return on investment for these young adults and their families, but they acknowledged that until they had evidence to prove that this was the case, programs would be in danger of budgetary cuts in times of fiscal constraints. In order to begin to secure funding for this concept, the development of state and federal policies that provide higher education with adequate funding needs to be undertaken. This will ensure that postsecondary programs for young adults with ID will be established throughout the nation.

The theme of funding was important throughout the analysis and was identified as an opportunity to provide support for these young adults with ID. The positive impact that this will have for these young adults was acknowledged by the entire group, thus allowing them to meet with academic and social success, and to be able to improve their overall quality of life.

\section{Program Design}

Effective and efficient design of any newly conceived program will help to ensure its success. A quote from the conference on postsecondary education for young adults with disabilities in regard to program design is as follows:

"It seems to me that successful programs, successful students are the ones that have huge amounts of supports. And the supports are very different from just someone who goes in to get an extended time on tests, and additional tutoring, these kinds of things in that you need social development, et cetera.”

This theme emerged as a constant thread in the development of postsecondary educational opportunities for young adults with ID. Through rich discussion of program design by the participants, the creation and implementation of programs for young adults with ID presented itself as a path forward to making the dream of a postsecondary educational environment become a reality.

Qualitative analysis of the transcripts presented the need to clearly define admission requirements for colleges and universities. These requirements would need to be inclusive of social skill development and the levels of mentoring needed when young adults with ID are admitted to a program. Along with admission requirements, clearly defined program goals and objectives need to be determined with the use of an established global outline for guidance. All stakeholders, including faculty, providers of disability services, parents, and young adults who are involved with a postsecondary program should have a clear understanding of the program and its expected outcomes for each participant. These program goals and objectives will act as a guide when developing individual goals and objectives that will meet the needs of each young adult.

In order to create a successful postsecondary educational program that addresses the needs of young adults with ID, multiple participants identified exploring the differences between various programs and the methods in which they are delivered. Through this process, the intentions of each program and the curriculum utilized can be identified. Replication of one of these programs is a possibility. However, the entire team felt that the key points from model programs (as described in current literature as well as model programs identified in the future) should be discussed and evaluated for use in the development 
of a distinguished postsecondary program. Success of each program design is dependent on the individual experiences of the young adults for which it is developed based on their individual experiences. Because of this, the focus group determined that the young adult's success should be defined in relationship to the program design to determine which young adults are successful and which are not. Barriers may be present that prevent young adults from accessing services. Once identified, these barriers need to be addressed with the program stakeholders for resolution. In order to gain further support for program design, data about the young adults with ID in these programs will need to be gathered. Through the aforementioned data, the possible presence of a connection between theory and postsecondary programs can be identified.

Identification of the culture of the program setting was a critical component of program design acknowledged by the group. Concerns about needs of the individuals involved with the program and their support, living arrangements, and instructors were discussed at length. Other concerns ranged from how supportive the culture in higher education is for these various PSE programs and how the transition from a mandated program (provided by the local education agency) to a competitive program would be most likely to occur. There is a distinction between PSE programs that are solely run by a university versus those that have an element of dual enrollment (students are still receiving educational services from their local high school simultaneously with participation in college/university courses). Stakeholders also pointed out that there is a third alternative: those programs that are run by the local education program but are located on a college campus. Each of these different programs faces different challenges for their connection to the rest of the campus environment.

Identification of a continuum of supports is needed to further improve PSE for students with ID and identify those that hold promise for employment and independent living outcomes for these individuals. This description of promising practices of supports may need to be mapped out as a path including exiting from the postsecondary education program. These stakeholders were recommending that a transition planning process to facilitate the movement from PSE programs to adult lives be identified. It should not be assumed that the same type of planning that occurs to facilitate the transition from high school to postsecondary education will be necessary. Instead, they were identifying this transition as one that will need to be addressed.

This emergent theme of program design was evident throughout the analysis and was identified as an important step in providing opportunities for young adults with ID. Stakeholders indicated that components of the program design were more likely determined by the amount of and source of funding and the outcomes the program staff believed to be most important. The focus group acknowledged the impact that a successful program design, based on evidence-based practices and anticipated outcomes, would provide for improvements to the overall quality of life for these young adults with ID.

\section{Research}

The need for research has been identified as an important factor with regard to postsecondary educational opportunities for young adults with ID. A quote concerning research from the conference on postsecondary education for these young adults is as follows:
"We really have to say that there is a real responsibility for us to establish some foundation of evidence for this embryonic practice that we hope will grow, but who knows."

Through the process of qualitative analysis of the transcripts, the focus group determined there is need for research in the area of postsecondary educational opportunities for young adults with ID, which is currently in its infancy stage. Visions of stakeholders need to be identified along with the potential benefits and incentives, as well as barriers to implementation in postsecondary institutions. Federal and agency involvement can provide guidance for university preparation and the impact that these programs may have on faculty and the student body.

Future research needs to be broad and comprehensive with studies that include comparisons across program types, identification of program participants, both external and internal supports that are needed for success, and establishment of program goals. Teacher preparation and appropriate program staffing were identified by the group as imperative for connecting all the grade levels with postsecondary education, thus making postsecondary opportunities a part of the continuum of services. Data collection on the critical variables identified by the individual teams can be used to document program effectiveness and thus provide support for future postsecondary programs for young adults with ID.

Research on the outcomes of creating social networks for young adults with ID through PSE experiences still needs to be conducted. The results may identify the current state of disability awareness and the impact that research on awareness may have on non-disabled young adults. Team members agreed that there is a need to expand the understanding of others in regard to disability being a form of diversity. Research that addresses education about disability awareness can provide documentation in regard to the amount of return on disability awareness. From these results, educational opportunities can be developed to expand awareness and support for the disability community.

Return on investment was a critical component identified by the team. Discussion centered on whether the cost for these future endeavors makes sense given the potential outcomes. Skill development and future opportunities for young adults and their families would be the return on investment. The team acknowledged that this return would have significant life changes for these young adults with ID, which could improve their overall quality of life.

The team members agreed that in order to expand the postsecondary opportunities for young adults with disabilities, support is needed from the federal, state, and local levels. Two supporters of this movement are the parents and young adults with ID as they are the major agents for change for this next disability movement.

\section{Limitations}

This study was a qualitative review of transcripts from a series of discussions about the state of PSE for students with ID from the practitioner, researcher and policymaker experts in the field. This study included only one data collection method although triangulation was achieved by having multiple researchers, with varying levels of prior knowledge of and support for PSE programs, participate in the data analysis process. Using these existing transcripts as the data for this study pro- 
vided insight into current practices in the field as well as the challenges to increasing the access to postsecondary education for students with ID, as discussed by this group of key stakeholders. However, these are initial findings and point to the need for further research that includes a range of data collection strategies to further expand the research on postsecondary education for students with ID.

Future studies can and should include multiple data collection methods including an opportunity to observe current practices and conduct follow-up interviews with participants to enhance the credibility of these findings. Despite these limitations, the findings of this study do provide a starting point for understanding what is happening in a field where there does not exist a significant evidence-base to guide current practice.

\section{Discussion}

As the field of PSE for persons with ID currently exists there is a rich mix of programs, from programs serving one or two students to 150 students, in vast range of learning environments, and using a variety of instructional and programmatic practices. The current heterogeneity of the PSE programs lends itself to a lack of clarity concerning common characteristics amongst programs. Group participants called for an "organizing of the fruit salad" that is these PSE programs. The data has truly brought to light how little communication there is among the variety of PSE programs and the critical need to supplement the various model programs in existence with systematic, highly rigorous research studies. In order to build this newly developed field, programs need to have a common language by which to communicate and common goals to work towards. There is also an intense need for programs to share successful strategies with others in the field. It is only through this active collaboration that the field will gain cohesion.

Second, this investigation has brought to light how important it is for the field of PSE for individuals with ID to clearly identify their anticipated outcomes and collect data to analyze their success in achieving them. To create sustainability of this movement, the field needs to be able to directly link these PSE programs to improved employment, income, independent living skills, and self-determination at a minimum. Understanding how to measure the impact of the PSE programs is essential. The field needs to continue to discuss what outcomes are desired out of the PSE experience for individuals with ID, as well as how those variables can be measured.

As this field is growing and developing, funding is crucial. In the United States current economic situation there are substantial cuts underway, particularly in the Fund for the Improvement of Postsecondary Education (FIPSE) programs in OPE. The Transition and Postsecondary Programs for Students with Intellectual Disabilities' (TPSID) are very labor intensive. Individual support professionals are needed in greater numbers, services need to be provided to very small groups of students, and often the investment in learning technology is substantial. Funding will always impact these PSE programs and considering how to braid multiple funding sources may provide the necessary supports to maintain these programs. Advocates in the field need to articulate to multiple agencies and stakeholders how vital funding is to providing equal access and participation for person with ID into PSE.

However, continued funding may not come without understanding the potential outcomes of these PSE programs, and understanding doesn't come without research. Continued research in this area is essential for the production and dissemination of knowledge about PSE for individuals with ID. Research should truly drive this growing field as we gain knowledge of effective practices and services for people with ID in PSE. To create a truly sustainable field we need to ask, research, and understand a variety of key questions including: What should a PSE program encompass? How will outcomes be measured and documented? How can information be shared? and How can the best programs be replicated?

\section{Conclusion}

There is growing interest in providing PSE for students with ID, as evident in the inclusion in the Higher Education Act of 2008, the funding of programs through the Transition Postsecondary programs for Students with ID (TPSID) from the Office of Postsecondary Education (OPE), and the continued growth in participation in subsequent conferences on PSE. These programs provide an opportunity to learn from experience, and movement forward will occur through continuing to fund such programs while continuing dialogue as a means of learning from each other and sharing program evaluation information describing what is working as well as challenges encountered. These PSE programs require enough time and monetary resources to implement a full array of services, to improve the implementation of those services, and to determine the impact and outcomes from this vastly different range of services. Lastly, there is a need to conduct rigorous research in the field to provide the conclusive evidence that program developers and funders can use to continue to move the field forward and improve the otherwise abysmal outcomes for individuals with ID.

This study highlights the recommendations of key stakeholders in the field of PSE for students with ID in 2009. Since that time, a number of these recommendations have been implemented. Annual conferences on PSE for students with ID are held annually at George Mason University, serving as a mechanism for program staff to share their experiences, policies, and procedures with each other. Colleagues at the University of Minnesota have taken on the task of creating a taxonomy to better understand a variety of program characteristics including: number of participants, types of coursework, types of accommodations and supports, and outcome measures (Institute on Community Integration, 2011). Other colleagues at the University of Massachusetts at Boston, under the auspices of a training and technical assistance project called Think College have developed a set of quality indicators used to help guide PSE programs to implement recommended practices to increase student participation/inclusion on college campuses (Grigal, Hart \& Weir, 2011). And research across programs has begun through a variety of different studies. However, despite the advancements in the field, the recommendations of these stakeholders continue to be relevant and provide impetus for increased funding for model program development as well as research.

\section{Acknowledgements}

This paper is intended to promote the exchange of ideas among researchers and policy makers. The views expressed in it are part of ongoing research and analysis and do not necessarily reflect the position of the U.S. Department of Education. 


\section{REFERENCES}

Baum, S., \& Ma, J. (2007). Education pays: The benefits of higher education for individuals and society. Washington, DC: The College Board.

Baum, S., \& Payea, K. (2004). Education pays: The benefits of higher education for individuals and society. Washington, DC: The College Board.

Casale-Giannola, D., \& Kamens, M. W. (2006). Inclusion at a university: Experiences of a young woman with Down syndrome. Mental Retardation, 44, 344-352. doi:10.1352/0047-6765(2006)44[344:IAAUEO]2.0.CO;2

Corbin, J. M., \& Strauss, A. (2008). Basics of qualitative research: Techniques and procedures for developing grounded theory (3rd ed.). Thousand Oaks, CA: Sage Publications.

Dolyniuk, C. A., Kamens, M. W., Corman, H., DiNardo, P. O., Totaro, R. M., \& Rockoff, J. C. (2002). Students with developmental disabilities go to college: Description of a collaborative transition project. Focus on Autism and Other Developmental Disabilities, 17, 236-241. doi:10.1177/10883576020170040601

Geertz, C. (1973). The interpretation of cultures. New York: Basic Books.

Grigal, M., Hart, D., \& Weir, C. (2011). Think college standards, quality indicators, and benchmarks for inclusive higher education. Boston, MA: University of Massachusetts Boston, Institute for Community Inclusion.

Hamill, L. B. (2003). Going to college: The experiences of a young woman with down syndrome. Mental Retardation, 41, 340-353. doi:10.1352/0047-6765(2003)41<340:GTCTEO>2.0.CO;2

Institute on Community Integration (2011). Postsecondary education for students with intellectual and developmental disabilities: A critical review of the state of knowledge and a taxonomy to guide future research. Minneapolis, MN: Research and Training Center.

Miller, G. (2007). H.R. 4137 (110th) Congress: Higher Education Opportunity Act. URL (last checked 31 July 2012).

http://www.govtrack.us/congress/bills/110/hr4137

McMahon, W.W. (2009). Higher learning, greater good: The private and social benefits of higher education. Baltimore, MD: Johns Hopkins University Press.

National Longitudinal Transition Study-2 (2003). People with disabili- ties and postsecondary education: Position paper. Washington, DC: Author.

Obama, B. (2009). Remarks of President Barack Obama-Address to joint session of Congress. URL.

http://www.whitehouse.gov/the_press_office/Remarks-of-PresidentBarack-Obama-Address-to-Joint-Session-of-Congress/

Perakyla, A. (2005). Analyzing talk and text. In N. K. Denzin, \& Y. S. Lincoln (Eds.), The sage handbook of qualitative research (pp. 869886). Thousand Oaks, CA: Sage.

Saldana, J. (2009). The coding manual for qualitative researchers. Thousand Oaks, CA: Sage.

State of the Science Conference on Postsecondary Education for Students with Intellectual Disabilities (2009). Co-sponsored by the $\mathrm{Na}$ tional Institute on Disability and Rehabilitation Research (NIDRR) and the Office of Postsecondary Education (OPE), US Department of Education. Fairfax, VA: George Mason University.

Stodden, R. A., Dowrick, P. W., Anderson, J., Heyer, K., \& Acosta, J. (2005). Postsecondary education across the USA: Experiences of adults with disabilities. Journal of Vocational Rehabilitation, 22, 4147.

Thoma, C. A., Lakin, K. C., Carlson, D., Domzal, C., Austin, K. M., \& Boyd, K. S. (2011). Participation in postsecondary education for students with intellectual disabilities: A review of the literature 20012010. Journal of Postsecondary Education and Disabilities, 24, 175 191.

US Census Bureau (2010). State and country quick facts. http:/quickfacts.census.gov/qfd/states/00000.html

US Department of Education (2010). US Secretary of Education Duncan announces \$10.9 million in awards under new programs that help students with intellectual disabilities transition to postsecondary education. URL (last checked 29 January 2011).

http://www.ed.gov/news/press-releases/us-secretary-education-dunca n-announces-109-million-awards-under-new-programs-he

Wenger, E. (1998). Communities of practice: Learning, meaning, and identity. Cambridge: Cambridge University Press.

Zafft, C., Hart, D., \& Zimbrich, K. (2004). College career connection: A study of youth with intellectual disabilities and the impact of postsecondary education. Education and Training in Developmental Disabilities, 1, 45-53. 